\title{
Resuscitation with $100 \%$ oxygen increases injury and counteracts the neuroprotective effect of therapeutic hypothermia in the neonatal rat
}

\author{
Marit L. Dalen', Xun Liu'², Maja Elstad ${ }^{2,3}$, Else Marit Løberg ${ }^{4}$, Ola D. Saugstad ${ }^{1}$, Terje Rootwelt ${ }^{5}$ and Marianne Thoresen ${ }^{2,3}$
}

INTRODUCTION: Mild therapeutic hypothermia (HT) reduces brain injury in survivors after perinatal asphyxia. Recent guidelines suggest that resuscitation of term infants should be started with air, but supplemental oxygen is still in use. It is not known whether supplemental oxygen during resuscitation affects the protection offered by subsequent HT.

RESULTS: Wilcoxon median (95\% confidence interval) hippocampal injury scores (range 0.0-4.0; 0 to $\geq 90 \%$ injury) were 21\% O normothermia (NT): 2.00 (1.25-2.50), 21\% O , HT: 1.00 (0.50-1.50), 100\% O NT: 2.50 (1.50-3.25), and 100\% O, HT: 2.00 (1.25-2.50). Although HT significantly reduced hippocampal injury $(B=-0.721, \operatorname{SEM}=0.297, P=0.018)$, reoxygenation with $100 \% \mathrm{O}_{2}$ increased injury $(B=+0.647$, SEM $=0.297, P=0.033)$. Regression constant $B=1.896$, SEM $=0.257$ and normally distributed residuals.

DISCUSSION: We confirm an 50\% neuroprotective effect of therapeutic HT in the neonatal rat. Reoxygenation with $100 \% \mathrm{O}_{2}$ increased injury and worsened reflex performance. HTwas neuroprotective whether applied after reoxygenation with air or 100\% $\mathrm{O}_{2}$. However, $\mathrm{HT}$ after $100 \% \mathrm{O}_{2}$ gave no net neuroprotection.

METHODS: In an established neonatal rat model, hypoxiaischemia $(\mathrm{HI})$ was followed by 30 -min reoxygenation in either $21 \% \mathrm{O}_{2}$ or $100 \% \mathrm{O}_{2}$ before $5 \mathrm{~h}$ of $\mathrm{NT}\left(37^{\circ} \mathrm{C}\right)$ or $\mathrm{HT}\left(32^{\circ} \mathrm{C}\right)$. The effects of $\mathrm{HT}$ and $100 \% \mathrm{O}_{2}$ on histopathologic injury in the hippocampus, basal ganglia, and cortex, and on postural reflex performance $7 \mathrm{~d}$ after the insult, were estimated by linear regression.

P erinatal asphyxia occurs in 1 to 6 per 1,000 term human births (1) and is an important cause of severe neurologic impairment and neonatal mortality. Therapeutic hypothermia (HT) has emerged as a neuroprotective therapy in both newborn animal models (2-4) and clinical trials (5-7). The collective evidence from these studies confirms that mild therapeutic HT improves outcome in hypoxic-ischemic encephalopathy, a condition in which $\sim 50 \%$ of cooled infants normally die or have significant neurologic disability (8) as compared with before the advent of HT treatment when $\sim 65 \%$ had poor outcome. In the UK, the National Institute for Health and Clinical Excellence has declared that HT should be used as standard of care after perinatal asphyxia (9). HT after perinatal asphyxia is also recommended by the recent 2010 International Resuscitation Guidelines (International Liaison Committee on Resuscitation) (10). HT suppresses many of the pathways that lead to delayed energy failure and cell death after hypoxia $(11,12)$, including generation of reactive oxygen species (13), excitotoxicity (14), and the inflammatory response (15).

Supplemental oxygen was previously recommended for resuscitation of the asphyxiated newborn infant, but after the changes in the 2010 International Liaison Committee on Resuscitation guidelines, it is now recommended that resuscitation of the term infant is best started with air, rather than pure oxygen (10). Evidence from animal studies shows that supplemental oxygen during resuscitation causes significant hyperoxia in the newborn brain $(16,17)$, with increased generation of reactive oxygen species (18), oxidative stress (19), inflammation (20), and cerebral injury (19,21,22). Clinical studies have shown that resuscitation with $100 \%$ oxygen has no advantage over air but causes increased mortality (23) and increased time to first breath and/ or cry (24-26).

It is not known whether supplemental oxygen during resuscitation affects hypothermic neuroprotection, but resuscitation with oxygen and HT have opposite effects on important contributors in the cascades after hypoxia-ischemia (HI), such as the generation of reactive oxygen species $(13,18)$ and the inflammatory response $(15,20)$. We used an established neonatal rat model to study whether air or $100 \%$ oxygen during 30-min reoxygenation after HI would affect the development of hypoxic-ischemic brain injury, and whether supplemental oxygen during reoxygenation would influence the neuroprotective effect of postresuscitation HT.

\section{RESULTS}

Sixty-four 7-d-old rats were randomized to the four treatment groups: 21-normothermia (NT; reoxygenation at $21 \%$ 
$\mathrm{O}_{2}$ followed by $5 \mathrm{~h}$ at $37^{\circ} \mathrm{C}$ ), 21- $\mathrm{HT}$ (reoxygenation at $21 \% \mathrm{O}_{2}$ followed by $5 \mathrm{~h}$ at $32^{\circ} \mathrm{C}$ ), $100-\mathrm{NT}$ (reoxygenation at $100 \%$ $\mathrm{O}_{2}$ followed by $5 \mathrm{~h}$ at $37^{\circ} \mathrm{C}$ ), and $100-\mathrm{HT}$ (reoxygenation at $100 \% \mathrm{O}_{2}$ followed by $5 \mathrm{~h}$ at $32^{\circ} \mathrm{C}$ ). No significant differences were found between groups regarding weight on the day of the insult, sex, or weight gain after the insult (Table 1). Median (95\% confidence interval) duration of anesthesia was 5.5 (5.0-6.0) $\mathrm{min}$, and the time between ligation and hypoxia was 107 (96-117) min. Regression analysis showed that sex, weight, and litter of pups did not significantly influence injury $(P>0.2)$.

Median (95\% confidence interval) histopathologic injury scores in the hippocampus, cortex, and basal ganglia are shown in Figure 1, whereas the raw data for the hippocampus are shown in Figure 2. The severity of injury in the 21-NT

Table 1. Animal characteristics

\begin{tabular}{lcccc}
\hline & $\begin{array}{c}21-\mathrm{NT} \\
(n=16)\end{array}$ & $\begin{array}{c}21-\mathrm{HT} \\
(n=18)\end{array}$ & $\begin{array}{c}100-\mathrm{NT} \\
(n=15)\end{array}$ & $\begin{array}{c}100-\mathrm{HT} \\
(n=15)\end{array}$ \\
\hline Weight & 10.6 & 10.6 & 10.3 & 10.3 \\
at P7 & $(9.5-11.6)$ & $(10.0-11.2)$ & $(9.3-11.2)$ & $(9.5-11.2)$ \\
Female & $63 \%$ & $61 \%$ & $60 \%$ & $53 \%$ \\
$\begin{array}{l}\text { Weight } \\
\text { gain at }\end{array}$ & $10.6(9.3-12.3)$ & $9.7(8.4-10.7)$ & $9.5(8.4-10.5)$ & $9.3(8.3-10.9)$ \\
P14 & & & & \\
\hline
\end{tabular}

Sixty-four 7-d-old (postnatal day 7, P7) rats were randomized to treatment after hypoxia-ischemia; $21=21 \% \mathrm{O}_{2} ; 100=100 \% \mathrm{O}_{2}$. Wilcoxon median ( $95 \% \mathrm{Cl}$ ) body weights in grams, and percentage female in each group.

$\mathrm{Cl}$, confidence interval; $\mathrm{HT}$, hypothermia; $\mathrm{NT}$, normothermia.

aExcluding five rats that died prematurely before postnatal day 14 (P14).

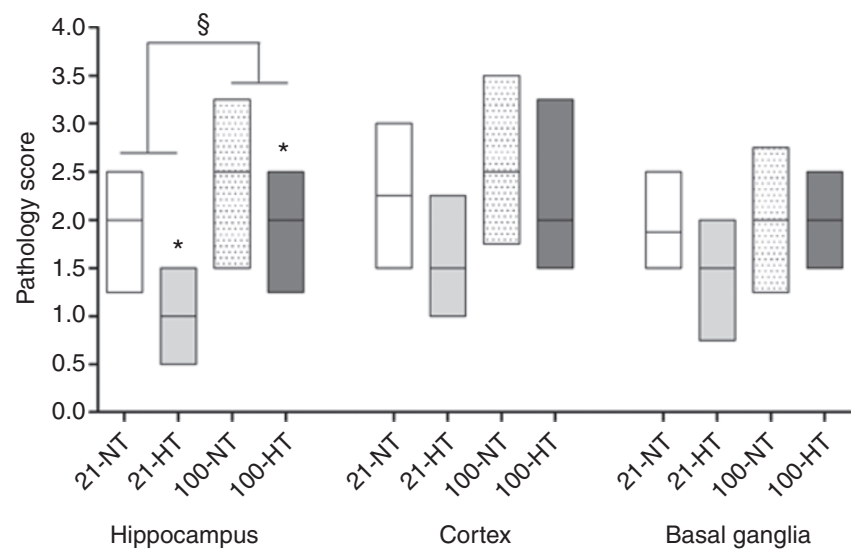

Figure 1. Pathology scores in the hippocampus, cortex, and basal ganglia. Wilcoxon median ( $95 \%$ confidence interval) pathology score in the hippocampus, cortex, and basal ganglia $7 \mathrm{~d}$ after the insult. Hippocampal injury was significantly reduced by hypothermia $(* P=0.018)$ and significantly increased by reoxygenation with $100 \% \mathrm{O}_{2}\left({ }^{5} P=0.033\right)$. Hypothermia significantly reduced injury whether the animals had been reoxygenated with $21 \% \mathrm{O}_{2}$ or $100 \% \mathrm{O}_{2^{\prime}}$ but there was no net protection after $100 \% \mathrm{O}_{2}$. The same trends were found in the cortex and basal ganglia but were not significant. The median values are almost identical to the values estimated by regression (Table 2); $21=21 \% \mathrm{O}_{2} ; 100=100 \% \mathrm{O}_{2} ; \mathrm{HT}$, hypothermia; NT, normothermia. Histopathology scores (range $0.0-4.0$, in 0.5 intervals) corresponding to degree of brain injury: $0.0-1.0=0-10 \% ; 1.0-2.0=10-30 \%$; $2.0-3.0=30-60 \% ; 3.0-4.0=60-90 \% ; 4 \geq 90 \%$. Unshaded bars, 21-NT; gray bars, 21-HT; dotted bars, 100-NT; dark bars, 100-HT. group was similar between the regions, with Wilcoxon median pathology scores of 2.0, 2.3, and 1.9 for the hippocampus, cortex, and basal ganglia, respectively (Figure 1). Table 2 shows the results from linear regression: HT significantly reduced hippocampal injury $(P=0.018)$, whereas $100 \% \mathrm{O}_{2}$ significantly increased injury $(P=0.033)$. Table 2 further shows that also for the cortex and basal ganglia, the injury scores were higher after $100 \% \mathrm{O}_{2}$ and lower after HT; however, the effects were not significant. HT significantly reduced hippocampal injury whether the animals had been reoxygenated with $21 \% \mathrm{O}_{2}$ or $100 \% \mathrm{O}_{2}$. However, because $100 \% \mathrm{O}_{2}$ increased injury, there was no net neuroprotection of $\mathrm{HT}$ after $100 \% \mathrm{O}_{2}$. ANOVA revealed no statistical interaction between the effects of HT and oxygen $(P=0.49)$.

Postural reflex performance (time to rotate $180^{\circ}$ from head down to head up in the negative geotaxis test) (Table 3) worsened with hyperoxia, as reoxygenation with $100 \% \mathrm{O}_{2}$ caused significantly increased time to rotate $180^{\circ}(P=0.016)$. The reduction in time to rotate observed in hypothermic animals did not reach statistical significance $(P=0.100)$. Median $(95 \%$ confidence interval) time in seconds to rotate $180^{\circ}$ were $21-\mathrm{NT}$ : 4.3 (2.9-5.7), 21-HT: 3.3 (2.3-4.1), 100-NT: 5.2 (4.5-6.5), and 100-HT: 4.5 (3.5-5.9).

\section{DISCUSSION}

The main finding of this study is that the neuroprotective effect of therapeutic HT is nearly fully negated by the increase in injury seen after breathing $100 \%$ oxygen during 30-min reoxygenation before the start of $\mathrm{HT}$. The effects of $\mathrm{HT}$ and of hyperoxic resuscitation have previously been studied separately. This is the first study to present data in a newborn survival model on the clinically relevant combination of supplemental oxygen during resuscitation and subsequent

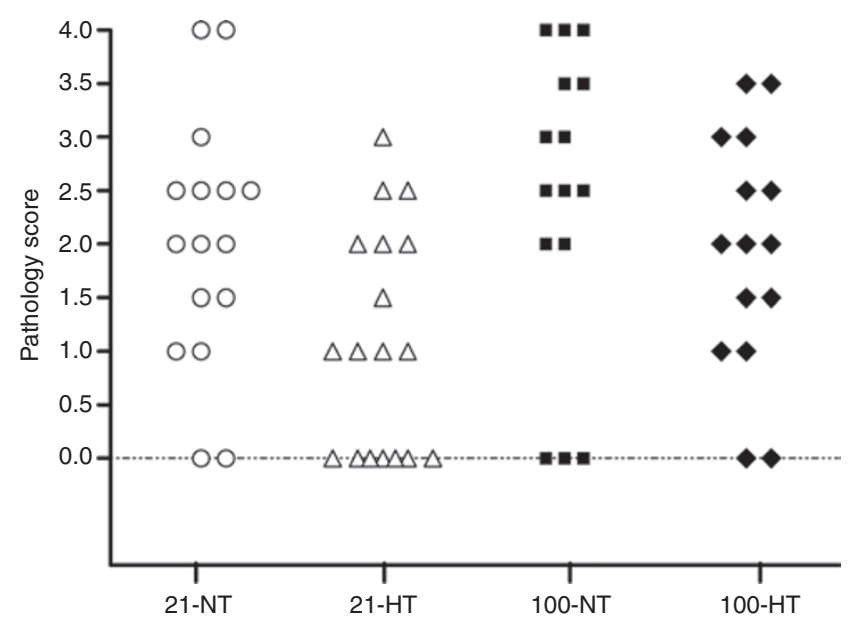

Figure 2. Distribution of individual pathology scores in the hippocampus. Individual pathology scores in the hippocampus of animals in the four groups. Histopathology scores (range $0.0-4.0$, in 0.5 intervals) corresponding to degree of brain injury: $0.0-1.0=0-10 \% ; 1.0-2.0=10-30 \%$; $2.0-3.0=30-60 \% ; 3.0-4.0=60-90 \% ; 4 \geq 90 \%$. Circles, $21-\mathrm{NT}$; triangles, 21-HT; squares, 100-NT; diamonds, $100-\mathrm{HT} ; 21=21 \% \mathrm{O}_{2} ; 100=100 \% \mathrm{O}_{2}$; $\mathrm{HT}$, hypothermia; NT, normothermia. 
Table 2. Effects of hyperoxia and hypothermia on pathology score

\begin{tabular}{|c|c|c|c|c|}
\hline Model & Coefficient & $95 \% \mathrm{Cl}$ & SEM & $P$ \\
\hline \multicolumn{5}{|l|}{ Hippocampus } \\
\hline Constant & 1.896 & $(1.383,2.410)$ & 0.257 & $<0.001$ \\
\hline Hypothermia & -0.721 & $(-1.314,-0.128)$ & 0.297 & $0.018^{a}$ \\
\hline $100 \% \mathrm{O}_{2}$ & +0.647 & $(0.054,1.241)$ & 0.297 & $0.033^{a}$ \\
\hline \multicolumn{5}{|l|}{ Cortex } \\
\hline Constant & 2.101 & $(1.481,2.721)$ & 0.310 & $<0.001$ \\
\hline Hypothermia & -0.385 & $(-1.101,0.331)$ & 0.358 & 0.286 \\
\hline $100 \% \mathrm{O}_{2}$ & +0.392 & $(-0.325,1.108)$ & 0.358 & 0.279 \\
\hline \multicolumn{5}{|l|}{ Basalganglia } \\
\hline Constant & 1.779 & $(1.316,2.242)$ & 0.232 & $<0.001$ \\
\hline Hypothermia & -0.305 & $(-0.840,0.230)$ & 0.268 & 0.259 \\
\hline $100 \% \mathrm{O}_{2}$ & +0.357 & $(-0.179,0.893)$ & 0.268 & 0.188 \\
\hline \multicolumn{5}{|c|}{$\begin{array}{l}\text { Linear regression showing the independent effects of hyperoxia and hypothermia } \\
\text { on pathology score. Dependent variable: neuropathology score in the hippocampus, } \\
\text { cortex, and basal ganglia } 1 \text { wk after hypoxia-ischemia. Independent variables: } \\
\text { temperature; hypothermia or normothermia; and oxygen; } 21 \% \mathrm{O}_{2} \text { or } 100 \% \mathrm{O}_{2} \text {. } \\
\text { The residuals were normally distributed. }\end{array}$} \\
\hline \multicolumn{5}{|c|}{$\mathrm{Cl}$, confidence interval. } \\
\hline aStatistical significan & & & & \\
\hline
\end{tabular}

Table 3. Effects of hyperoxia and hypothermia on postural reflex performance

\begin{tabular}{lcccc}
\hline Model & Coefficient & $95 \% \mathrm{Cl}$ & SEM & $P$ value \\
\hline Constant & 4.216 & $(3.303,5.129)$ & 0.457 & $<0.001$ \\
Hypothermia & -0.881 & $(-1.936,0.174)$ & 0.527 & 0.100 \\
$100 \% \mathrm{O}_{2}$ & +1.304 & $(0.248,2.360)$ & 0.528 & $\mathbf{0 . 0 1 6}^{\mathrm{a}}$ \\
\hline
\end{tabular}

Linear regression showing the independent effects of hyperoxia and hypothermia on postural reflex performance (negative geotaxis test) $1 \mathrm{wk}$ after hypoxia-ischemia. Dependent variable: best time in seconds to rotate $180^{\circ}$ from head-down to head-up position on a $45^{\circ}$ slope. Independent variables: temperature; hypothermia or normothermia; and oxygen; $21 \% \mathrm{O}_{2}$ or $100 \% \mathrm{O}_{2}$. The residuals were normally distributed.

$\mathrm{Cl}$, confidence interval.

astatistical significance.

therapeutic HT. We confirm an $\sim 50 \%$ neuroprotective effect of therapeutic HT after reoxygenation with $21 \% \mathrm{O}_{2}$ in the neonatal rat hippocampus $1 \mathrm{wk}$ after HI. We also confirm an $\sim 25 \%$ detrimental effect of hyperoxic resuscitation. Of note, breathing $100 \% \mathrm{O}_{2}$ for $30 \mathrm{~min}$ after hypoxia, but before $\mathrm{HT}$, increased injury nearly as much as HT protected from injury, resulting in no net neuroprotection when HT followed hyperoxia. The best outcome was seen when HT followed reoxygenation with air, and the worst scores were seen when NT followed reoxygenation with $100 \% \mathrm{O}_{2}$.

Although the effects of HT and hyperoxia were most pronounced in the hippocampus, the effects of reduced injury due to HT and increased injury due to hyperoxic reoxygenation were seen also in the cortex and basal ganglia, but did not reach statistical significance. The hippocampus is one of the most sensitive regions for hypoxic injury and is relatively more injured in the neonatal rodent models $(27,28)$. To mimic the clinical setting in which resuscitation precedes therapeutic HT, we introduced a 30-min delay for administration of $100 \%$ $\mathrm{O}_{2}$ or $21 \% \mathrm{O}_{2}$ before $\mathrm{HT}$ in this experiment. We speculate that this delay, together with an increased in core temperature from $36^{\circ} \mathrm{C}$ to $37^{\circ} \mathrm{C}$ during reoxygenation, may have reduced the magnitude of hypothermic protection in this experiment. Thus, the sample size might have been too small to detect statistically significant neuroprotection in the cortex and basal ganglia.

We report increased brain injury after 30-min reoxygenation with $100 \% \mathrm{O}_{2}$ after a $\mathrm{HI}$ insult. This is in line with results in a newborn mouse survival model, in which $30 \mathrm{~min}$ of $100 \% \mathrm{O}_{2}$ after hypoxia caused increased brain injury, disrupted myelination, and accumulation of nitrotyrosine (19). We chose $30 \mathrm{~min}$ of reoxygenation because this is a typical resuscitation time used clinically. In contrast to our results, other investigators found no difference in brain injury in rats after reoxygenation with $100 \%$ oxygen vs. air (29), or even reduced injury after $100 \%$ oxygen in mice (30). Of note, the results in the latter study may have been distorted because more animals in the $100 \% \mathrm{O}_{2}$ group died prematurely and were excluded from the analyses.

The postural reflex examined in the negative geotaxis test was significantly slower in animals reoxygenated with $100 \% \mathrm{O}_{2}$ after the insult, whereas there was a tendency toward improved performance after HT, although not statistically significant. Thus, the pathology results were supported by neurologic performance, which we have also shown previously in neuroprotective studies with both short- and long-term survival (31-33).

These results are in line with studies showing protective effects of HT $(2-4,11-15)$ and with studies demonstrating harmful effects of hyperoxic reoxygenation (18-21). The new and important knowledge added by this study is the effect of the combination of these two important interventions recommended by the International Liaison Committee on Resuscitation guidelines (10). A recent study in a short-termsurvival newborn pig model (16) suggested that the protective effect of HT was stronger after hyperoxia. However, in the present study, there was no indication that the protective effect of HT was more pronounced after hyperoxia. The results rather suggest that $\mathrm{HT}$ is effective both after $21 \% \mathrm{O}_{2}$ and $100 \% \mathrm{O}_{2}$, but that the starting point after hyperoxic reoxygenation is worse and HT ameliorates the injury caused by hyperoxia. Although HT and hyperoxia have opposite effects on important contributors in the cascades after HI injury, it is possible that part of hyperoxic injury is more immediate and cannot be completely reduced by subsequent HT. The lack of an interaction between oxygen concentration during reoxygenation and postreoxygenation temperature shows that there was no difference in magnitude of effect of HT between the two reoxygenation groups.

The Rice-Vannucci model is the most frequently used model of neonatal brain injury. It is a selective brain injury model and does not allow for examination of the systemic and multiorgan effects of hyperoxia and HT after HI. These findings therefore need to be confirmed in a large animal model 
in which effects on the whole body can be studied. Despite its limitations, results from this neonatal rat model have been reproduced in larger models such as the newborn pig and the fetal sheep and have been confirmed in large clinical randomized trials.

We conclude that hyperoxic reoxygenation causes increased brain injury and that HT is significantly neuroprotective after both normoxic and hyperoxic reoxygenation. Because there was no net protection of HT after hyperoxia, one way to optimize outcome after HI could be to avoid hyperoxia before therapeutic HT.

\section{METHODS}

All procedures were performed under Home Office license in accordance with UK regulations as approved by the University of Bristol animal ethical review panel. The Rice-Vannucci neonatal HI rat model has been in use for more than $30 \mathrm{y}$ (34). It is a unilateral hemispheric stroke model based on ischemia (ligation of the left common carotid artery) followed by hypoxia (90 min in a hypoxic chamber of $8 \%$ oxygen). The maturation of the rat brain at postnatal day 7 is "near term-equivalent" to the human. Neuroprotection from postinsult HT after both short- and long-term survival has previously been shown in the postnatal day 7 rat model $(31,35)$. Hypothermic protection was further confirmed in newborn pigs $(2-3,36)$ and fetal sheep $(4,37)$ before successful clinical trials of therapeutic HT (5-7). For the postnatal day 7 rat model to show long-term neuroprotection, at least $3 \mathrm{~h}$ of $5^{\circ} \mathrm{C}$ reduction in core temperature is needed $(31-33,38)$. We reduced experimental variability by brief duration of anesthesia (median $5.5 \mathrm{~min}$; two experienced researchers performing ligations in parallel), short duration $(<180 \mathrm{~min})$ between carotid ligation and the beginning of hypoxia, and tightly controlled temperature, oxygen, and $\mathrm{CO}_{2}$ levels in our specially designed exposure chamber (32). The chamber temperature was servo-controlled to target rectal temperature, which was continuously monitored $\left(<0.1^{\circ} \mathrm{C}\right.$ deviation) in one probe animal in each chamber (CritiCool; MTRE, Yavne, Israel).

\section{Procedures}

Ligation of the left carotid artery was performed under general anesthesia (isoflurane, $3.5 \%$ induction, $1.5 \%$ maintenance, in $\mathrm{NO}_{2} / \mathrm{O}_{2}$ $(2: 1)$ ), followed by $<180$-min recovery with the dam. Five animals died during surgery and were excluded from the analyses. Seventytwo postnatal day 7 Wistar rats of both sexes from six litters were subjected to hypoxia $\left(8 \% \mathrm{O}_{2}\right.$ in $\left.\mathrm{N}_{2}\right)$ for $90 \mathrm{~min}$ at a rectal temperature of $36.0^{\circ} \mathrm{C}$ (Figure 3 ). Four temperature probe rats were excluded from all analyses because the stress of carrying a rectal probe may affect outcome (39). Four rats died during hypoxia, before randomization and treatment allocation, and were excluded from the analyses. The 64 pups that survived the hypoxic challenge were randomized, allowing all litters equal representation in each of the four groups. Pups were also randomized between groups for weight and sex. After hypoxia, groups 1-4 were randomized to one of four postinsult treatment groups receiving either $21 \% \mathrm{O}_{2}$ or $100 \% \mathrm{O}_{2}$ before NT or HT: 21-NT, 21-HT, 100-NT, and 100-HT. The 100-NT and 100-HT groups received initial 30-min reoxygenation with $100 \% \mathrm{O}_{2}$ at $37^{\circ} \mathrm{C}$, followed by $5 \mathrm{~h}$ of breathing $21 \% \mathrm{O}_{2}$ at either NT $\left(37^{\circ} \mathrm{C}\right)$ or HT $\left(32^{\circ} \mathrm{C}\right)$. The $21-\mathrm{NT}$ and $21-\mathrm{HT}$ groups received initial $30-\mathrm{min}$ reoxygenation with $21 \% \mathrm{O}_{2}$ at $37^{\circ} \mathrm{C}$, followed by $5 \mathrm{~h}$ of either NT $\left(37^{\circ} \mathrm{C}\right)$ or $\mathrm{HT}\left(32^{\circ} \mathrm{C}\right)$. After $5 \mathrm{~h}$ of NT or HT, the pups were returned to the dam and maintained in a $12: 12 \mathrm{~h}$ dark/light cycle at an environmental temperature of $22^{\circ} \mathrm{C}$ with adequate food and water. The weight of each pup was recorded daily to detect failure to thrive as an indicator of injury. Animals that continued to lose weight and died between day 4 and 7 after the insult (postnatal days 11-14; one 21-NT, no 21-HT, one 100-NT, and three 100-HT) were considered as premature deaths. Because both death and disability are main outcomes in clinical asphyxia studies, we also included animals with

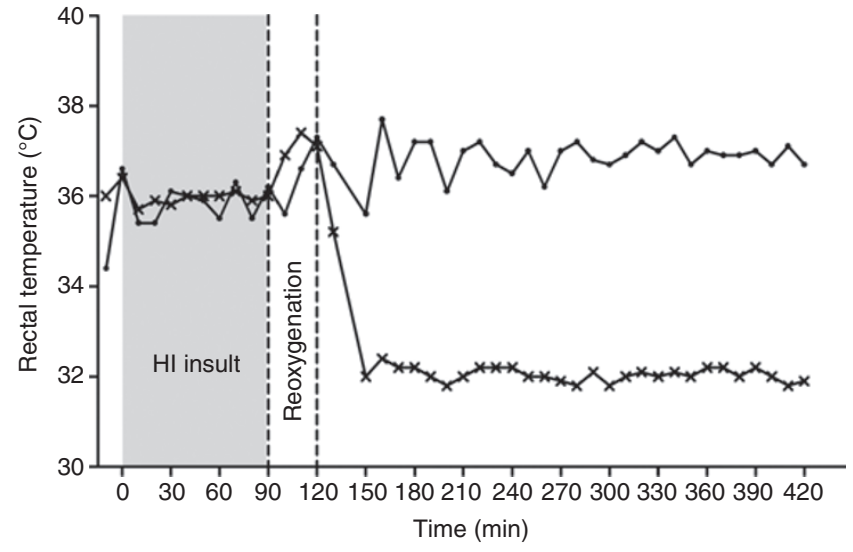

Figure 3. Experimental design and rectal temperature recordings during the experiment. Rectal temperature recordings in temperature probe rats - two typical individual traces. Experimental design: unilateral carotid ligation and 90 -min hypoxic exposure at $36^{\circ} \mathrm{C}$ in a chamber with $8 \% \mathrm{O}_{2}$ ( $\mathrm{HI}$ insult), before 30 -min reoxygenation at $37^{\circ} \mathrm{C}$ in pure oxygen $\left(100 \% \mathrm{O}_{2}\right)$ or air $\left(21 \% \mathrm{O}_{2}\right)$, followed by 5 -h recovery at $37^{\circ} \mathrm{C}(\mathrm{NT})$ or $32^{\circ} \mathrm{C}(\mathrm{HT})$. This resulted in four groups: $21-\mathrm{NT}, 21-\mathrm{HT}, 100-\mathrm{NT}$, and 100-HT. Shaded circles, NT; multiplication symbols, HT. HI, hypoxia-ischemia; HT, hypothermia; NT, normothermia.

premature death in the analyses. These animals were given a pathology score similar to that of the worst outcome in a survivor from the same litter and treatment group.

\section{Early Behavioral Testing (Negative Geotaxis Test)}

At 2 wk of age, 1 wk after the HI insult, the animals were subjected to the negative geotaxis test, which tests an innate postural reflex that develops while the eyes are still fused in the second week of life in healthy rat pups. This test is the short-term survival test that correlates best with both short- and long-term pathology and long-term functional outcome (staircase test) in the postnatal day 7 rat model used in this study (32). The rats were placed with the head down on a $45^{\circ}$ slope, and the time taken to rotate $180^{\circ}$ to a head-up position was recorded $(32,40)$. The shortest time out of three attempts was used for statistical analysis. Testing was performed by an individual unaware of treatment allocation.

\section{Histopathology}

At 2 wk of age, 1 wk after the $\mathrm{HI}$ insult, transcardiac perfusion with $4 \%$ phosphate-buffered $(0.1 \mathrm{~mol} / \mathrm{l})$ formaldehyde was performed under deep isoflurane $/ \mathrm{N}_{2} \mathrm{O}$ anesthesia. The brains were kept in $4 \%$ formaldehyde until further processing. Coronal 3-mm blocks were cut through the brain using a standard matrix for uniformity (ASI Instruments, Warren, MI) and were embedded in paraffin. Blocks were sectioned at $3 \mu \mathrm{m}$ and stained with hematoxylin and eosin. A pathologist blinded to treatment allocation evaluated the degree of brain injury in three regions (cortex, basal ganglia, and hippocampus) using a validated scoring system with a nine-step scale from 0.0 (no injury) to 4.0 ( $\geq 90 \%$ injury) (35). This scoring scale has been validated against cell counting previously and is also used by other investigators $(35,38,41)$.

\section{Statistics}

Statistical analyses were performed with SPSS version 17 (SPSS, Chicago, IL) and StatExact (Cytel Studio 7; Cytel, Cambridge, MA). Because histopathologic and neurologic test data were skewed, nonparametric tests (Wilcoxon-Mann-Whitney test and HodgesLehman estimates of median) were used for comparisons between groups (42). Data are given as Wilcoxon median (95\% confidence interval) unless otherwise specified. Effects of HT, hyperoxia, sex, weight, and litter of pups on histopathologic injury score in the brain and on neurologic testing were estimated by linear regression. 
The regression analysis was supplemented by ANOVA to assess whether there was an interaction between the effects of hyperoxia and HT. Two-sided testing with $P<0.05$ was considered statistically significant.

\section{ACKNOWLEDGMENTS}

We thank Lars Walløe for advice on the statistical analysis, Emma ScullBrown and Nicholas Hoque for assistance with the experiments, and Grethe Dyrhaug and Ingeborg Løstegaard Goverud for preparing the histopathology slides.

\section{STATEMENT OF FINANCIAL SUPPORT}

This study was supported by Action Medical Research (UK), SPARKS (UK), Laerdal Foundation for Acute Medicine (Norway), The Norwegian Research Council, Nevronor, Children's Foundation at Oslo University Hospital, Ella and Robert Wenzin Foundation at the University of Oslo, and S.G. Sønneland Foundation, Oslo.

Disclosure: The authors declare no conflict of interest.

\section{REFERENCES}

1. McGuire W. Perinatal asphyxia. Clin Evid (Online) 2007;pii:0320.

2. Tooley JR, Satas S, Porter H, Silver IA, Thoresen M. Head cooling with mild systemic hypothermia in anesthetized piglets is neuroprotective. Ann Neurol 2003;53:65-72.

3. Thoresen M, Penrice J, Lorek A, et al. Mild hypothermia after severe transient hypoxia-ischemia ameliorates delayed cerebral energy failure in the newborn piglet. Pediatr Res 1995;37:667-70.

4. Gunn AJ, Gunn TR, de Haan HH, Williams CE, Gluckman PD. Dramatic neuronal rescue with prolonged selective head cooling after ischemia in fetal lambs. J Clin Invest 1997;99:248-56.

5. Shankaran S, Laptook AR, Ehrenkranz RA, et al. Whole-body hypothermia for neonates with hypoxic-ischemic encephalopathy. N Engl J Med 2005; 353:1574-84

6. Azzopardi DV, Strohm B, Edwards AD, et al. Moderate hypothermia to treat perinatal asphyxial encephalopathy. N Engl J Med 2009;361: 1349-58.

7. Gluckman PD, Wyatt JS, Azzopardi D, et al. Selective head cooling with mild systemic hypothermia after neonatal encephalopathy: multicentre randomised trial. Lancet 2005;365:663-70.

8. Edwards AD, Brocklehurst P, Gunn AJ, et al. Neurological outcomes at 18 months of age after moderate hypothermia for perinatal hypoxic ischaemic encephalopathy: synthesis and meta-analysis of trial data. BMJ 2010;340:c363.

9. National Institute for Health and Clinical Excellence, interventional procedure guidance. Therapeutic hypothermia with intracorporeal temperature monitoring for hypoxic perinatal brain injury. <http://www. nice.org.uk/nicemedia/live/11315/48809/48809.pdf> Accessed 26 May 2010.

10. Perlman JM, Wyllie J, Kattwinkel J, et al. Part 11: Neonatal resuscitation: 2010 International Consensus on Cardiopulmonary Resuscitation and Emergency Cardiovascular Care Science With Treatment Recommendations. Circulation 2010;122:16 Suppl 2:S516-38.

11. Edwards AD, Yue X, Squier MV, et al. Specific inhibition of apoptosis after cerebral hypoxia-ischaemia by moderate post-insult hypothermia. Biochem Biophys Res Commun 1995;217:1193-9.

12. Erecinska M, Thoresen M, Silver IA. Effects of hypothermia on energy metabolism in Mammalian central nervous system. J Cereb Blood Flow Metab 2003;23:513-30.

13. Horiguchi T, Shimizu K, Ogino M, Suga S, Inamasu J, Kawase T. Postischemic hypothermia inhibits the generation of hydroxyl radical following transient forebrain ischemia in rats. J Neurotrauma 2003;20:511-20.

14. Thoresen M, Satas S, Puka-Sundvall M, et al. Post-hypoxic hypothermia reduces cerebrocortical release of $\mathrm{NO}$ and excitotoxins. Neuroreport 1997;8:3359-62.
15. Deng H, Han HS, Cheng D, Sun GH, Yenari MA. Mild hypothermia inhibits inflammation after experimental stroke and brain inflammation. Stroke 2003;34:2495-501.

16. Dalen ML, Alme TN, Munkeby BH, et al. Early protective effect of hypothermia in newborn pigs after hyperoxic, but not after normoxic, reoxygenation. J Perinat Med 2010;38:545-56.

17. Linner R, Werner O, Perez-de-Sa V, Cunha-Goncalves D. Circulatory recovery is as fast with air ventilation as with $100 \%$ oxygen after asphyxiainduced cardiac arrest in piglets. Pediatr Res 2009;66:391-4.

18. Kutzsche S, Ilves P, Kirkeby OJ, Saugstad OD. Hydrogen peroxide production in leukocytes during cerebral hypoxia and reoxygenation with $100 \%$ or $21 \%$ oxygen in newborn piglets. Pediatr Res 2001;49: 834-42.

19. Koch JD, Miles DK, Gilley JA, Yang CP, Kernie SG. Brief exposure to hyperoxia depletes the glial progenitor pool and impairs functional recovery after hypoxic-ischemic brain injury. J Cereb Blood Flow Metab 2008;28:1294-306.

20. Markus T, Hansson S, Amer-Wåhlin I, Hellström-Westas L, Saugstad OD, Ley D. Cerebral inflammatory response after fetal asphyxia and hyperoxic resuscitation in newborn sheep. Pediatr Res 2007;62:71-7.

21. Vereczki V, Martin E, Rosenthal RE, Hof PR, Hoffman GE, Fiskum G. Normoxic resuscitation after cardiac arrest protects against hippocampal oxidative stress, metabolic dysfunction, and neuronal death. J Cereb Blood Flow Metab 2006;26:821-35.

22. Andresen JH, Solberg R, Løberg EM, Munkeby BH, Stray-Pedersen B, Saugstad OD. Resuscitation with 21 or $100 \%$ oxygen in hypoxic nicotinepretreated newborn piglets: possible neuroprotective effects of nicotine. Neonatology 2008;93:36-44.

23. Saugstad OD, Ramji S, Soll RF, Vento M. Resuscitation of newborn infants with $21 \%$ or $100 \%$ oxygen: an updated systematic review and meta-analysis. Neonatology 2008;94:176-82.

24. Saugstad OD, Rootwelt T, Aalen O. Resuscitation of asphyxiated newborn infants with room air or oxygen: an international controlled trial: the Resair 2 study. Pediatrics 1998;102:e1.

25. Ramji S, Ahuja S, Thirupuram S, Rootwelt T, Rooth G, Saugstad OD. Resuscitation of asphyxic newborn infants with room air or $100 \%$ oxygen. Pediatr Res 1993;34:809-12.

26. Vento M, Asensi M, Sastre J, García-Sala F, Pallardó FV, Viña J. Resuscitation with room air instead of $100 \%$ oxygen prevents oxidative stress in moderately asphyxiated term neonates. Pediatrics 2001;107:642-7.

27. Ota A, Ikeda T, Ikenoue T, Toshimori K. Sequence of neuronal responses assessed by immunohistochemistry in the newborn rat brain after hypoxia-ischemia. Am J Obstet Gynecol 1997;177:519-26.

28. Mallard EC, Gunn AJ, Williams CE, Johnston BM, Gluckman PD. Transient umbilical cord occlusion causes hippocampal damage in the fetal sheep. Am J Obstet Gynecol 1992;167:1423-30.

29. Grafe MR, Woodworth KN, Noppens K, Perez-Polo JR. Long-term histological outcome after post-hypoxic treatment with $100 \%$ or $40 \%$ oxygen in a model of perinatal hypoxic-ischemic brain injury. Int J Dev Neurosci 2008;26:119-24.

30. Presti AL, Kishkurno SV, Slinko SK, et al. Reoxygenation with $100 \%$ oxygen versus room air: late neuroanatomical and neurofunctional outcome in neonatal mice with hypoxic-ischemic brain injury. Pediatr Res 2006;60:55-9.

31. Bona E, Hagberg H, Løberg EM, Bågenholm R, Thoresen M. Protective effects of moderate hypothermia after neonatal hypoxia-ischemia: short- and long-term outcome. Pediatr Res 1998;43:738-45.

32. Hobbs C, Thoresen M, Tucker A, Aquilina K, Chakkarapani E, Dingley J. Xenon and hypothermia combine additively, offering long-term functional and histopathologic neuroprotection after neonatal hypoxia/ischemia. Stroke 2008;39:1307-13.

33. Thoresen M, Hobbs CE, Wood T, Chakkarapani E, Dingley J. Cooling combined with immediate or delayed xenon inhalation provides equivalent long-term neuroprotection after neonatal hypoxia-ischemia. J Cereb Blood Flow Metab 2009;29:707-14.

34. Rice JE 3rd, Vannucci RC, Brierley JB. The influence of immaturity on hypoxic-ischemic brain damage in the rat. Ann Neurol 1981;9:131-41. 


\section{Articles | Dalen et al.}

35. Thoresen M, Bågenholm R, Løberg EM, Apricena F, Kjellmer I. Posthypoxic cooling of neonatal rats provides protection against brain injury. Arch Dis Child Fetal Neonatal Ed 1996;74:F3-9.

36. Haaland K, Løberg EM, Steen PA, Thoresen M. Posthypoxic hypothermia in newborn piglets. Pediatr Res 1997;41(4 Pt 1):505-12.

37. Gunn AJ, Gunn TR, Gunning MI, Williams CE, Gluckman PD. Neuroprotection with prolonged head cooling started before postischemic seizures in fetal sheep. Pediatrics 1998;102:1098-106.

38. Trescher WH, Ishiwa S, Johnston MV. Brief post-hypoxic-ischemic hypothermia markedly delays neonatal brain injury. Brain Dev 1997;19:326-38.
39. Thoresen M, Bågenholm R, Løberg EM, Apriccna F. The stress of being restrained reduces brain damage after a hypoxic-ischaemic insult in the 7-day-old rat. Neuroreport 1996;7:481-4.

40. Lubics A, Reglodi D, Tamás A, et al. Neurological reflexes and early motor behavior in rats subjected to neonatal hypoxic-ischemic injury. Behav Brain Res 2005; 157:157-65.

41. Thoresen M, Haaland K, Løberg EM, et al. A piglet survival model of posthypoxic encephalopathy. Pediatr Res 1996;40:738-48.

42. Hollander M, Wolfe DA. Nonparametric Statistical Methods. New York, NY: Wiley, 1999:787. 